\title{
Hypocalcemia is a distinctive biochemical feature of hospitalized COVID-19 patients
}

\author{
Luigi di Filippo ${ }^{1}$ - Anna Maria Formenti ${ }^{1}$ Mauro Doga ${ }^{1}$ - Stefano Frara ${ }^{1}$ - Patrizia Rovere-Querini ${ }^{2}$. \\ Emanuele Bosi ${ }^{2} \cdot$ Michele Carlucci $^{3} \cdot$ Andrea Giustina $^{1}{ }^{1}$
}

Received: 16 October 2020 / Accepted: 27 October 2020 / Published online: 9 November 2020

(c) Springer Science+Business Media, LLC, part of Springer Nature 2020

Hypocalcemia has been recently identified as one of the major biochemical features of COVID-19 patients [1-7].

To date, several studies reported high frequency of hypocalcemia with both low ionized and total calcium levels in different cohorts of COVID-19 patients in emergency departments (ED) and during hospitalization. In some instances, also severe cases of hypocalcemia were reported [1-7]. Moreover, a strong association between lower calcium and higher levels of inflammatory parameters with increased disease severity has also been reported [1]. Finally, some authors identified hypocalcemia as a relevant and independent risk factor for worse clinical outcome including rate of hospitalization, ICU admission, and mortality $[1,5,6]$.

In a previous study, in patients positive for nasopharyngeal swabs SARS-CoV-2 real-time reverse-transcriptase polymerase chain reaction (RT-qPCR) test, lower total and ionized calcium levels as compared to those admitted in ED with same clinical signs and symptoms and negative to RTqPCR test were reported [4]. However, no clinical, biochemical, and disease severity parameters were reported for these two groups making difficult an accurate comparison.

The aim of our study was to compare, for the first time in the literature, ionized calcium levels between two groups of patients hospitalized in the same period of the year with

Andrea Giustina

giustina.andrea@hsr.it

1 Institute of Endocrine and Metabolic Sciences, Vita-Salute San Raffaele University and IRCCS San Raffaele Hospital, Milan, Italy

2 Vita-Salute San Raffaele University and Division of Immunology, Transplantation and Infectious Diseases, IRCCS San Raffaele Scientific Hospital, Milan, Italy

3 Emergency Department, IRCCS San Raffaele Scientific Hospital, Milan, Italy severe acute respiratory infections COVID-19 and nonCOVID-19 related.

\section{Methods}

We conducted a retrospective cohort study at IRCCS San Raffaele Hospital, a tertiary health-care hospital in Milan, Italy. We included patients (aged $\geq 18$ years) with acute respiratory infectious diseases related to COVID-19 (CoV) and not related to COVID-19 (nCoV) hospitalized during the same study period (March-June 2020). We excluded patients transferred from other hospitals and patients initially hospitalized for other diseases.

Confirmed COVID-19 was defined as positive RT-qPCR from a nasal and/or throat swab together with signs, symptoms, and radiological findings suggestive of COVID-19 pneumonia.

Patients initially identified as negative for COVID-19 and successively positive at RT-qPCR or patients initially hospitalized for $\mathrm{nCoV}$ and then superinfected with SARSCoV-2 were excluded from the study.

Only patients with serum ionized calcium levels data from arterial blood gas tests performed at initial evaluation in the ED were included. Ionized calcium levels were expressed both as actually measured levels ("actual calcium" AC) and as adjusted mathematically to a standardized $\mathrm{pH}$ of 7.4 levels ("standardized calcium" SC) to avoid influence of sample handling. Hypocalcemia was defined as calcium level below $1.18 \mathrm{mmol} / \mathrm{L}$ (RapidPoint 500 Analyzer, VA, USA).

We excluded patients with comorbidities and concomitant therapies influencing calcium metabolism: chronic kidney disease, osteoporosis, patients on glucocorticoids and antiepileptic drugs, vitamin D/calcium, loop/thiazide diuretics, and patients with an estimated glomerular filtration rate $(\mathrm{eGFR}) \leq 30 \mathrm{~mL} / \mathrm{min} / 1.73 \mathrm{~m}^{2}$ using creatinine levels at initial evaluation. 
This study is part of the COVID-19 Biobank study, which is registered with ClinicalTrials.gov, NCT04318366 and obtained specific approval by the local EC [8].

Statistical analysis was conducted with SPSS 23.0 version (Chicago, USA). Categorical variables were indicated as frequency (\%) and continuous variables as medians (IQR).

Differences in variable frequencies between groups were calculated using the Fisher test and the Mann-Whitney $U$ test for continuous variables. All statistical tests were two sided. A $p$ value of $<0.05$ was considered statistically significant.

\section{Results}

A total of 20 non-COVID-19 patients were included in the study. These patients were matched with 20 COVID-19 patients (part of a previously reported cohort [1]) for the following known prognostic factors: age, sex, and concomitant comorbidities distribution.

Demographic and clinical patient characteristics are summarized in Table 1. Median [IQR] age was 72.5 years [68.2-86] in nCoV patients and 73.5 years [67.5-83.2] in CoV patients $(p=0.93)$ (Table 1). Fifty percent of patients in both groups were males $(p=1)$ (Table 1). The main comorbidities were history of arterial hypertension $(70 \%$ in $\mathrm{nCoV}$ and $65 \%$ in $\mathrm{CoV}, p=0.73$ ), followed by diabetes mellitus (25\% in $\mathrm{nCoV}$ and $35 \%$ in $\mathrm{CoV}, p=0.73)$, coronary artery disease $(25 \%$ in $\mathrm{nCoV}$ and $20 \%$ in $\mathrm{CoV}, p=$ $1)$, chronic obstructive pulmonary disease $(20 \%$ in $\mathrm{nCoV}$ and $15 \%$ in $\mathrm{CoV}, p=1)$, and active neoplasms (15\% in $\mathrm{nCoV}$ and $15 \%$ in $\mathrm{CoV}, p=1$ ) (Table 1).

No statistical differences were found between the two groups regarding the inflammatory and organ injury parameters levels, as for serum creatinine and eGFR (Table 1).

Patients affected by COVID-19 presented a worse respiratory distress with a lower $\mathrm{PaO} 2 / \mathrm{FiO} 2$ and $\mathrm{SpO} 2 / \mathrm{FiO} 2$ ratios (calculated as the ratio between the arterial partial pressure or saturation of oxygen measured on arterial blood gas test and the fraction of inspired oxygen) compared to non-COVID-19 patients (Table 1).

A total of eight (40\%) and seven (35\%) non-COVID-19 patients were hypocalcemic using actual ionized calcium (AC) and standardized ionized calcium (SC) levels, respectively (Table 1). A total of $16(80 \%)$ and $15(75 \%)$ COVID-19 patients were hypocalcemic using AC and SC, respectively (Table 1). Compared to nCoV patients, hypocalcemia in $\mathrm{CoV}$ cohort was found statistically more frequent ( $p=0.022$ using AC; $p=0.025$ using SC) (Table 1).

Lower calcium levels were statistically found in $\mathrm{CoV}$ patients compared to $\mathrm{nCoV}$ group (AC: $1.18 \mathrm{mmol} / \mathrm{L}$ [1.12-1.2] in $\mathrm{nCoV}$ vs. $1.11 \mathrm{mmol} / \mathrm{L}$ [1.06-1.16] in $\mathrm{CoV}$,
Table 1 Comparison of clinical and biochemical parameters between non-COVID and COVID hospitalized patients

Non-
COVID (n.20)

Clinical and

$p$ value

biochemical variables

\begin{tabular}{|c|c|c|c|}
\hline Age (years) & $72.5[68.2-86]$ & $73.5[67.5-83.2]$ & 0.93 \\
\hline Male gender $(\%)$ & $10(50)$ & $10(50)$ & 1 \\
\hline BMI & 26.7 [23.3-30.6] & $28.4[18.7-30]$ & 0.56 \\
\hline Hypertension (\%) & $14(70)$ & $13(65)$ & 0.73 \\
\hline $\begin{array}{l}\text { Coronary artery } \\
\text { disease }(\%)\end{array}$ & $5(25)$ & $4(20)$ & 1 \\
\hline COPD $(\%)$ & $4(20)$ & $3(15)$ & 1 \\
\hline Diabetes $(\%)$ & $5(25)$ & $7(35)$ & 0.73 \\
\hline Cancer $^{\mathrm{a}}(\%)$ & $3(15)$ & $3(15)$ & 1 \\
\hline $\mathrm{CRP}(\mathrm{mg} / \mathrm{L})$ & $113[50-157]$ & $52[28.5-141]$ & 0.24 \\
\hline LDH (U/L) & $295[228.5-431]$ & 357 [244-488] & 0.39 \\
\hline $\begin{array}{l}\text { Serum lactate } \\
(\mathrm{mmol} / \mathrm{L})\end{array}$ & $1.05[0.9-1.67]$ & $1.25[0.99-1.87]$ & 0.29 \\
\hline Creatinine (mg/dL) & 0.89 [0.64-1.18] & $0.91[0.78-1.26]$ & 0.57 \\
\hline $\begin{array}{l}\text { eGFR } \\
\left(\mathrm{mL} / \mathrm{min} / 1.73 \mathrm{~m}^{2}\right)\end{array}$ & 74 [49-93] & 69 [56-84] & 0.63 \\
\hline $\begin{array}{l}\text { Tympanic } \\
\text { temperature }\left({ }^{\circ} \mathrm{C}\right)\end{array}$ & $37[36.2-37.7]$ & $37.4[36.6-37.9]$ & 0.44 \\
\hline Arterial $\mathrm{pH}$ & $7.46[7.42-7.5]$ & $7.46[7.44-7.48]$ & 0.76 \\
\hline $\mathrm{paO} 2 / \mathrm{fiO} 2$ ratio & $\begin{array}{l}323.6 \\
{[271.2-404.8]}\end{array}$ & $\begin{array}{l}277.4 \\
{[233.3-308.3]}\end{array}$ & 0.041 \\
\hline satO2/fiO2 ratio & $\begin{array}{l}450 \\
{[428.6-458.3]}\end{array}$ & $\begin{array}{l}433.3 \\
{[363.9-442.8]}\end{array}$ & 0.007 \\
\hline $\begin{array}{l}\text { AC ionized calcium } \\
(\mathrm{mmol} / \mathrm{L})\end{array}$ & $1.18[1.12-1.2]$ & $1.11[1.06-1.16]$ & 0.02 \\
\hline $\begin{array}{l}\mathrm{AC} \\
\text { Hypocalcemia (\%) }\end{array}$ & $8(40)$ & $16(80)$ & 0.022 \\
\hline $\begin{array}{l}\text { SC ionized calcium } \\
(\mathrm{mmol} / \mathrm{L})\end{array}$ & $1.19[1.14-1.22]$ & $1.13[1.09-1.17]$ & 0.006 \\
\hline SC hypocalcemia $(\%)$ & $7(35)$ & $15(75)$ & 0.025 \\
\hline
\end{tabular}

${ }^{\mathrm{a}}$ Only active neoplasms were included in this study.

$B M I$ body mass index, $C O P D$ chronic obstructive pulmonary disease, $C R P$ C-reactive protein, $L D H$ lactate dehydrogenase, $e G F R$ estimated glomerular filtration rate, calculated using the CKD-EPI equation, $A C$ actual ionized calcium levels, $S C$ standardized ionized calcium levels Continuous variables are reported as medians (IQR)

$P$ values reported in bold are those statistically significant

$p=0.02 ;$ SC: $1.19 \mathrm{mmol} / \mathrm{L}[1.14-1.22]$ in $\mathrm{nCoV}$ vs. $1.13 \mathrm{mmol} / \mathrm{L}$ [1.09-1.17] in CoV, $p=0.006$ ) (Table 1).

On admission in ED, 15 patients (37.5\%) (7 in $\mathrm{CoV}$ and 8 in $\mathrm{nCoV}$ group) had an eGFR from 30 to $60 \mathrm{~mL} / \mathrm{min} /$ $1.73 \mathrm{~m}^{2}$. No statistical differences were found between patients with eGFR lower and higher than $60 \mathrm{~mL} / \mathrm{min}$ regarding ionized calcium levels (AC: $1.13 \mathrm{mmol} / \mathrm{L}$ [1.1-1.17] in $<60 \mathrm{~mL} / \mathrm{min}$ group vs. $1.17 \mathrm{mmol} / \mathrm{L}$ [1.1-1.2] in $\geq 60 \mathrm{~mL} / \mathrm{min}, p=0.26$; SC: $1.15 \mathrm{mmol} / \mathrm{L}$ [1.1-1.18] in 
Table 2 Comparison of $\mathrm{PaO} 2 / \mathrm{FiO} 2$ and $\mathrm{SpO} 2 / \mathrm{FiO} 2$ ratios between hypocalcemic and normocalcemic patients in COVID and non-COVID groups

\begin{tabular}{llll}
\hline Panel a & Hypocalcemic (AC) & Normocalcemic (AC) & $p$ value \\
\hline $\begin{array}{llll}\text { PaO2/FiO2 ratio } \\
\text { COVID }\end{array}$ & $266[214-303]$ & $304[282-366]$ & 0.14 \\
$\begin{array}{l}\text { Non-COVID } \\
\text { SpO2/FiO2 ratio }\end{array}$ & $354[246-398]$ & $309[276-410]$ & 0.63 \\
COVID & $419[348-442]$ & $442[442-453]$ & 0.08 \\
Non-COVID & $450[417-457]$ & $450[439-461]$ & 0.51 \\
\hline Panel b & Hypocalcemic (SC) & Normocalcemic (SC) & $p$ value \\
\hline PaO2/FiO2 ratio & & & \\
COVID & $257[208-304]$ & $300[285-347]$ & 0.13 \\
Non-COVID & $328[238-404]$ & $318[278-404]$ & 0.54 \\
SpO2/FiO2 ratio & & & \\
COVID & $419[346-442]$ & $442[442-452]$ & 0.06 \\
Non-COVID & $447[414-457]$ & $452[442-462]$ & 0.33 \\
\hline
\end{tabular}

$<60 \mathrm{~mL} / \mathrm{min}$ group vs. $1.18 \mathrm{mmol} / \mathrm{L}[1.12-1.21]$ in $\geq 60 \mathrm{~mL} /$ $\min , p=0.33$ ).

Linear regression analyses showed no statistical significant correlations of calcium levels with $\mathrm{PaO} 2 / \mathrm{FiO} 2$ and $\mathrm{SpO} 2 / \mathrm{FiO} 2$ ratios in $\mathrm{CoV}$ patients $(\mathrm{PaO} 2 / \mathrm{FiO} 2: \mathrm{AC} p=0.2$, $\mathrm{SC} p=0.13$; SpO2/FiO2: AC $p=0.35$, SC $p=0.29)$ and no significant differences were found between hypocalcemic and normocalcemic patients in both $\mathrm{nCoV}$ and $\mathrm{CoV}$ groups regarding these two ratios, although a tendency to a higher impact of hypocalcemia was noted in COVID-19 patients. (Table 2).

\section{Discussion}

To the best of our knowledge, this is the first study comparing the occurrence of hypocalcemia and calcium levels in two matched groups of hospitalized patients for COVID19 and non-COVID-19 infectious respiratory diseases. We found a higher rate of hypocalcemia with lower calcium levels in $\mathrm{CoV}$ compared to $\mathrm{nCoV}$ patients.

Rate of hypocalcemia occurring in our $\mathrm{CoV}$ study population was similar to other epidemiological data reported in previous studies, which found an, at least initially, unexpected high frequency of hypocalcemia [1-7].

Hypocalcemia was an already reported finding in patients hospitalized in Internal Medicine departments [9] and was found quite consistently to be associated with increased risk of acute respiratory failure and mortality $[10,11]$. Therefore, it is currently unclear if hypocalcemia in COVID-19 is only a marker of disease severity rather than a specific feature of the disease. This open issue also impacts on the clinical and prognostic significance of this biochemical finding.
In a previous study, lower calcium levels were reported in patients positive to SARS-CoV-2 RT-qPCR test as compared to negative patients, hypothesizing a direct influence of viral infection on calcium metabolism [4]. However, no comparative clinical data were reported and thus also in this case a possible influence of differences in disease severity on calcium levels could not be excluded.

Therefore, in order to understand if hypocalcemia may be a distinctive feature of COVID-19 we thought of interest to compare calcium levels in hospitalized $\mathrm{CoV}$ and $\mathrm{nCoV}$ patients matched for main anthropometric, biochemical, and clinical features.

Inflammatory parameters, as CRP and LDH levels, were found to be negatively associated with calcium levels and, in different cohorts of COVID-19 patients, hypocalcemia and lower calcium levels resulted as an independent risk factor for worse clinical outcome, including hospitalization, ICU admission, and mortality. In order to reduce possible confounding influences of known COVID-19 prognostic factors as age, gender, and presence of concomitant comorbidities [12], we compared calcium levels in patients admitted to our ED for acute respiratory illness during the same period of time with or without SARS-CoV-2 infection matched for the above characteristics on an one case-one control basis.

Despite the same baseline clinical characteristics and inflammatory parameters of the two groups, we found a much higher rate of hypocalcemia with lower calcium levels in $\mathrm{CoV}$ patients compared to $\mathrm{nCoV}$. Confirming the epidemiological data on SARS-CoV-2 infection, $\mathrm{CoV}$ patients were characterized by a worse respiratory distress compared to $\mathrm{nCoV}$ [12].

Our data confirm previous studies that reported hypocalcemia in hospitalized patients with acute illness [13]. However, the rate of hypocalcemia was doubled in COVID19 patients matched for baseline anthropometric and clinical features. Therefore, the very high frequency of hypocalcemia seems to be a distinctive feature of SARS-CoV infections [14] and in particular of COVID-19. Pathophysiologically, it can be hypothesized that specific viral mechanisms that influence calcium handling [15-17] in the presence of widespread vitamin D deficiency [18-22] may contribute to specifically lowering calcium in the disease. Clinically, it may be hypothesized that low calcium levels may be one neglected determinant, as well as hypovitaminosis D [23, 24], of COVID-19 respiratory complications and mortality.

Therefore, serum calcium (and vitamin D) may be thought to be potential target for intervention in hospitalized COVID-19 patients who have been recently reported to be at high risk of vertebral fractures [7, 25-27]. Interestingly, we have recently reported that women with osteoporosis treated with vitamin $\mathrm{D}$ did not seem to be at increased risk 
of severe COVID-19 despite treatment with antiosteoporotic drugs potentially predisposing to both infections and hypocalcemia [28].

One main limitation of our study is the limited number of patients with $\mathrm{nCoV}$ respiratory infection admitted to ED. However, it should be underlined that this is a remarkable cohort given the overwhelming number of COVID-19 patients hospitalized in that same study period. Other limitations of our report include the lack of outcome data, of clinical features possibly related to hypocalcemia, of calcium and vitamin D data during hospitalization as well as information on calcium (and vitamin D) administration in these patients.

In conclusion, our study suggests that hypocalcemia may be a distinctive biochemical feature of COVID-19 potentially impacting on disease clinical severity and representing a novel possible treatment target worth to be tested in this clinical setting.

\section{Data availability}

All authors had full access to all the data in the study and takes responsibility for the integrity of the data and the accuracy of the data analysis

Author contributions All authors contributed equally.

\section{Compliance with ethical standards}

Conflict of interest The authors declare that they have no conflict of interest.

Ethical approval All procedures performed in studies involving human participants were in accordance with the ethical standards of the institutional and/or national research committee and with the 1964 Helsinki declaration and its later amendments or comparable ethical standards.

Informed consent Written informed consent was waived.

Publisher's note Springer Nature remains neutral with regard to jurisdictional claims in published maps and institutional affiliations.

\section{References}

1. L. Di Filippo, A.M. Formenti, P. Rovere-Querini et al. Hypocalcemia is highly prevalent and predicts hospitalization in patients with COVID-19. Endocrine 68(3), 475-478 (2020)

2. L. Di Filippo, A.M. Formenti, A. Giustina, Hypocalcemia: the quest for the cause of a major biochemical feature of COVID-19. Endocrine (2020) https://doi.org/10.1007/s12020-020-02525-9

3. S. Bossoni, L. Chiesa, A. Giustina, Severe hypocalcemia in a thyroidectomized woman with Covid-19 infection. Endocrine 68 (2), 253-254 (2020)

4. F. Cappellini, R. Brivio, M. Casati, A. Cavallero, E. Contro, P. Brambilla, Low levels of total and ionized calcium in blood of
COVID-19 patients. Clin. Chem. Lab. Med. 58(9), e171-173 (2020).

5. J. Liu, P. Han, J. Wu, J. Gong, D. Tian, Prevalence and predictive value of hypocalcemia in severe COVID-19 patients. J. Infect. Public Health 13(9), 1224-1228 (2020). https://doi.org/10.1016/j. jiph.2020.05.029

6. J.K. Sun, W.H. Zhang, L. Zou et al. Serum calcium as a biomarker of clinical severity and prognosis in patients with coronavirus disease 2019. Aging 12(12), 11287-11295 (2020). https://doi.org/ 10.18632/aging.103526

7. L. Di Filippo, A.M. Formenti, M. Doga, E. Pedone, P. RovereQuerini, A. Giustina, Radiological Thoracic Vertebral Fractures are highly prevalent in COVID-19 and predict disease outcomes. J Clin Endocrinol Metab (2020). https://doi.org/10.1210/clinem/dgaa738

8. P. Rovere-Querini, C. Tresoldi, C. Conte et al. Biobanking for COVID-19 research. Panminerva Med. 2020. https://doi.org/10. 23736/S0031-0808.20.04168-3. Epub ahead of print

9. A. Akirov, A. Gorshtein, I. Shraga-Slutzky, I. Shimon, Calcium levels on admission and before discharge are associated with mortality risk in hospitalized patients. Endocrine 57(2), 344-351 (2017). https://doi.org/10.1007/s12020-017-1353-y

10. C. Thongprayoon, W. Cheungpasitporn, A. Chewcharat, M.A. Mao, K.B. Kashani, Serum ionised calcium and the risk of acute respiratory failure in hospitalised patients: a single-centre cohort study in the USA. BMJ Open 10(3), e034325 (2020). https://doi. org/10.1136/bmjopen-2019-034325

11. C. Thongprayoon, W. Cheungpasitporn, A. Chewcharat, M.A. Mao, S. Thirunavukkarasu, K.B. Kashani, Hospital mortality and long-term mortality among hospitalized patients with various admission serum ionized calcium levels. Postgrad. Med. 132(4), 385-390 (2020). https://doi.org/10.1080/00325481.2020.1728980

12. S. Richardson, J.S. Hirsch, M. Narasimhan et al. Presenting characteristics, comorbidities, and outcomes among 5700 patients hospitalized with COVID-19 in the New York City Area. JAMA 323(20), 2052-2059 (2020).

13. A. Kelly, M.A. Levine, Hypocalcemia in the critically ill patient. J. Intensive Care Med. 28(3), 166-177 (2013). https://doi.org/10. 1177/0885066611411543

14. C.M. Booth, L.M. Matukas, G.A. Tomlinson et al. Clinical features and short-term outcomes of 144 patients with SARS in the greater Toronto area. JAMA 289(21), 2801-2809 (2003). https:// doi.org/10.1001/jama.289.21.JOC30885

15. Y. Zhou, T.K. Frey, J.J. Yang, Viral calciomics: interplays between $\mathrm{Ca} 2+$ and virus. Cell Calcium 46(1), 1-17 (2009). https://doi.org/10.1016/j.ceca.2009.05.005

16. J.K. Millet, G.R. Whittaker, Physiological and molecular triggers for SARS-CoV membrane fusion and entry into host cells. Virology 517, 3-8 (2018). https://doi.org/10.1016/j.virol.2017.12.015

17. M.R. Straus, T. Tang, A.L. Lai, A. Flegel, M. Bidon, J.H. Freed, S. Daniel, G.R.Ca2 Whittaker, Ions promote fusion of middle east respiratory syndrome coronavirus with host cells and increase infectivity. J. Virol. 94(13), e00426-20 (2020). https://doi.org/10. 1128/JVI.00426-20

18. A. Giustina, R.A. Adler, N. Binkley et al. Controversies in vitamin D: summary statement from an international conference. J. Clin. Endocrinol. Metab. 104(2), 234-240 (2019). https://doi.org/ 10.1210/jc.2018-01414

19. A. Giustina, R.A. Adler, N. Binkley, J. Bollerslev, R. Bouillon, B. Dawson-Hughes, P.R. Ebeling, D. Feldman, A.M. Formenti, M. Lazaretti-Castro, C. Marcocci, R. Rizzoli, C.T. Sempos, J.P. Bilezikian, Consensus statement from 2nd International Conference on Controversies in Vitamin D. Rev. Endocr. Metab. Disord. 21(1), 89-116 (2020). https://doi.org/10.1007/s11154-019-09532-w

20. A. D'Avolio, V. Avataneo, A. Manca et al. 25-hydroxyvitamin D concentrations are lower in patients with positive PCR for SARSCoV-2. Nutrients 12(5), E1359 (2020) 
21. A. Giustina, A.M. Formenti, Preventing a covid-19 pandemic can high prevalence of severe hypovitaminosis D play a role in the high impact of Covid infection in Italy? BMJ 368, m810 (2020)

22. P.C. Ilie, S. Stefanescu, L. Smith, The role of vitamin D in the prevention of coronavirus disease 2019 infection and mortality. Aging Clin Exp Res. 32(7), 1195-1198 (2020). https://doi.org/10. 1007/s40520-020-01570-8

23. J.P. Bilezikian, D. Bikle, M. Hewison et al., MECHANISMS IN ENDOCRINOLOGY: vitamin D and COVID-19. Eur. J. Endocrinol. (2020). https://doi.org/10.1530/EJE-20-0665

24. A. Giustina, R. Bouillon, N. Binkley et al. Controversies in vitamin D: a statement from the 3rd International Conference. JBMR Plus (2020). https://doi.org/10.1002/jbm4.10417
25. M. Puig-Domingo, M. Marazuela, A. Giustina, COVID-19 and endocrine diseases. A statement from the European Society of Endocrinology. Endocrine 68(1), 2-5 (2020)

26. M. Marazuela, A. Giustina, M. Puig-Domingo, Endocrine and metabolic aspects of the COVID-19 pandemic. Rev. Endocr. Metab. Disord. 1-13 (2020). https://doi.org/10.1007/s11154-020-09569-2

27. V.P Singh, B. Khatua, B. El-Kurdi, C. Rood, Mechanistic basis and therapeutic relevance of hypocalcemia during severe COVID19 infection. Endocrine. 1-2 (2020). https://doi.org/10.1007/ s12020-020-02530-y. Epub ahead of print

28. A.M. Formenti, E. Pedone, L. di Filippo, F.M. Ulivieri, A. Giustina, Are women with osteoporosis treated with denosumab at risk of severe COVID-19? Endocrine 1-3 (2020). https://doi.org/ 10.1007/s12020-020-02500-4 